\title{
Construções de Estrutura Argumental com Argumento Preposicionado: uma modelagem linguístico-computacional na FrameNet Brasil
}

\author{
Vânia Gomes de Almeida ${ }^{1}$, Tiago Timponi Torrent ${ }^{2}$ \\ ${ }^{1}$ Doutoranda em Linguística - Universidade Federal de Juiz de Fora \\ ${ }^{2}$ Professor Associado - Universidade Federal de Juiz de Fora - Juiz de Fora, MG - \\ Brasil \\ vania.almeidadestudante.ufjf.br, tiago.torrent@ufjf.edu.br
}

\begin{abstract}
Resumo. Este trabalho apresenta uma proposta para representar computacionalmente as construções Transitiva Indireta, Transitiva Oblíqua e Bitransitiva do Português Brasileiro, no âmbito do Constructicon da FrameNet Brasil. Dessa forma, demonstra de que maneira as teorias irmãs da Semântica de Frames e da Gramática das Construções podem contribuir na busca por um modelo de língua que alie forma e sentido em uma única representação.
\end{abstract}

\begin{abstract}
This work presents a proposal to computationally represent the Indirect Transitive, Oblique Transitive and Ditransitive constructions of Brazilian Portuguese, in the framework of the Constructicon of FrameNet Brasil. In this way, it demonstrates how the sister theories of Frame Semantics and Construction Grammar can contribute to the quest for a language model bringing together form and meaning in one same representation.
\end{abstract}

\section{Introdução}

Este trabalho tem como objetivo a apresentação de uma proposta de investigação de uma modelagem linguístico-computacional de construções de estrutura argumental no Português Brasileiro (PB). Tal proposta se enquadra nas discussões teóricometodológicas da FrameNet Brasil (FN-Br) (SALOMÃO, 2009). A FN-Br está envolvida em vários campos de pesquisa, que incluem desde a construção de recursos lexicais à identificação e catalogação de construções. A FrameNet começou em 1997 como um projeto de lexicografia computacional para o inglês, liderado por Charles J. Fillmore no International Computer Science Institute, em Berkeley, Califórnia. Desde então, o recurso original vem expandindo sua cobertura de unidades lexicais para outros idiomas, como espanhol, alemão, sueco, japonês e português do Brasil. Nos projetos afiliados à FrameNet de Berkeley, os frames e Elementos de Frames são expandidos para os outros idiomas, ou seja, é utilizada a estrutura definida para o inglês como ponto de partida para a descrição do idioma de destino com adaptações e mudanças na estrutura original.

Diante disso, a FN-Br conta com dois grandes recursos computacionais: um Lexicon e um Constructicon. O Lexicon tem por objetivos: criar uma representação computacional de frames, definidos por seus participantes e instrumentos e conectados entre si via relações entre frames; definir Unidades Lexicais (ULs), pareamentos entre um lema e um significado definido em termos de um frame; anotar sentenças que exemplifiquem os padrões de valência sintáticos e semânticos em que as ULs ocorrem. Como frames são representações de estruturas cognitivas, definidas, de acordo com 
Fillmore (1982), como um sistema de conceitos relacionados de tal forma que, para entender qualquer um deles, é necessário tem que entender toda a estrutura na qual ele se encaixa, as análises realizadas para as ULs, portanto, nos fornecem a descrição de suas propriedades de valência sintática e semântica

Já o Constructicon visa à criação de um recurso para a descrição das características semânticas e gramaticais de construções do PB, incorporando descrições interpretáveis computacionalmente para cada construção, oferecendo informações semânticas e especificando as relações entre as construções. Lexicon e Constructicon se encontram conectados porque ambos descrevem satisfatoriamente as principais propriedades dos fenômenos linguísticos, na medida em que itens lexicais são construções e são, portanto, licenciados por construções lexicais, e que tanto itens lexicais quanto construções não lexicais podem evocar frames, que constituem o cerne de uma FrameNet.

Diante da interligação entre as duas frentes da FN-Br, apresentamos uma proposta que pretende ampliar o que foi apresentado em Almeida (2016) e em Diniz da Costa et al. (2018), em que buscou-se apresentar a modelagem de um conjunto de 11 construções de estrutura argumental do PB de modo a aprimorar o Constructicon da FN-Br, sendo elas: Sujeito_predicado, Transitiva_direta_ativa, Intransitiva, Ergativa, Predicativa_nominal, Predicativa_nominal_atributiva, Predicativa_nominal_estativa, Predicativa_locativa, Mudança_de_estado, Argumento_cindido e Objeto_interdito. Mais especificamente, debruçamo-nos sobre três construções de estrutura argumental que possuem argumentos preposicionados: Transitiva_indireta, Transitiva_oblíqua e Bitransitiva.

\section{A Gramática de Construções}

A Gramática de Construções (GC) é um desenvolvimento recente na teoria linguística, começou a ser discutida mais intensamente no final dos anos 80 e início dos anos 90 com os trabalhos de Fillmore, Kay e O'Connor (1988), Goldberg (1995), Kay e Fillmore (1999) e Croft (2001).

Nesse contexto, as principais acepções da GC são: construções são unidades básicas da língua que se constituem em correspondências entre forma e significado (GOLDBERG, 1995; KAY e FILLMORE, 1999); qualquer material linguístico desde o mais simples ao mais complexo pode ser considerado uma construção, havendo uma continuidade entre o léxico e a sintaxe; a gramática de uma língua consiste de uma rede de construções mediada por diferentes relações (FILLMORE, 2008).

Há diversas abordagens que utilizam essas acepções básicas da GC, sendo talvez o modelo mais conhecido o apresentado por Goldberg $(1995,2006)$, que propõe um modelo baseado na interação entre semântica verbal e a semântica construcional. Com esse modelo, não é necessário apresentar vários sentidos verbais para explicar a diferença entre as construções de estrutura argumental.

O modelo de Goldberg (1995) para a GC desenvolveu-se em uma produtiva interface com a área de aquisição da linguagem (GOLDBERG, 2006). Esse modelo, entretanto, possui limitações de formalização, que tornam difícil sua aplicação para além da fase linguística do processo de modelagem computacional ${ }^{1}$. Nesse sentido, o modelo

\footnotetext{
${ }^{1}$ Dias da Silva (2006) apresenta três fases como necessárias para o desenvolvimento de um sistema em Linguística Computacional: a fase linguística, a fase linguístico-computacional e a fase computacional. Neste trabalho, a primeira apresenta a especificação das construções, a segunda, a representação dessas construções no Constructicon e a fase computacional propõe a projeção de um sistema computacional para que essas construções possam ser reconhecidas posteriormente.
} 
da GC baseado em unificação proposto por Fillmore, Kay e O'Connor (1988), por Kay e Fillmore (1999), Fillmore (2008) e Fillmore (2013), a Gramática de Construções de Berkeley (BCG), revela-se mais adequado para o objeto deste trabalho.

O que a BCG traz de diferente de outros modelos de GC é o fato de ser um modelo de gramática que integra os padrões sintáticos e semânticos das expressões linguísticas às noções da Semântica de Frames (FILLMORE, 1982; 1985), fornecendo um formalismo baseado em unificação, que é relevante para a proposta de desenvolvimento de recursos como Constructicons e para tarefas de Compreensão de Língua Natural.

\section{O Constructicon da FrameNet Brasil}

Seguindo o proposto na BCG (FILLMORE, 2013), o Constructicon foi criado com o intuito de representar computacionalmente determinadas estruturas linguísticas não processáveis lexicograficamente e, por isso, abarca o conhecimento linguístico que excede a valência simples de palavras simples (FILLMORE, 2008). De modo mais específico, descreve construções em termos de suas propriedades gramaticais e seu potencial semântico. A iniciativa de criação de um modelo computacional de construções foi seguida também pela FN-Br que, desde 2010, desenvolve um Constructicon para o PB (TORRENT ET AL. 2014; SILVA ET AL., 2017).

No Constructicon, uma construção é mapeada formalmente, unificando-a, quando relevante, a um frame específico. Portanto, para desenvolver o Constructicon de acordo com os princípios da Semântica de Frames e da Gramática de Construções, foi necessário: (i) fornecer um meio de ligar construções a frames da mesma maneira que Unidades Lexicais estão conectadas a frames, (ii) modelar relações entre construções, de modo que o recurso possa fornecer como resultado uma rede de construções, e não uma lista delas, (iii) definir restrições sintático-semânticas que possibilitem a descrição dessas construções computacionalmente.

Diante disso, o Constructicon conta hoje com dois tipos de relações - Herança e Evocação - e com restrições - Constraints - de modo a apresentar linguística e computacionalmente as principais características de construções no PB.

A primeira relação, Herança construcional, conecta uma construção à sua construção mãe, ou seja, ela é modelada seguindo Kay e Fillmore (1999). Nesse contexto, o modo completo de herança presume que a construção herdeira é um tipo mais específico da construção mãe. Essa relação fornece a possibilidade de armazenar informações de modo econômico e não redundante, tratando a herança pelo viés da cópia virtual de informação, isto é, a informação herdada é registrada somente na construção dominante, o que evita a redundância no armazenamento de dados. Assim, a construção filha contém todas as informações da construção mãe e mais outras informações adicionais.

A segunda relação, Evocação, conecta uma construção a um ou mais frames que ela pode evocar. Diferentemente da Herança, a relação de Evocação não implica que o frame evocado seja "mãe" da construção que o evoca, isto é, essa não necessita conter toda a estrutura de seu esquema "mãe". Assim, o frame evocado pela construção é evidenciado através do mapeamento entre os Elementos de Construção e os Elementos de Frame que a construção evoca.

As construções no Constructicon da FN-Br também são definidas em termos de restrições ou constraints. Na base de dados, uma restrição é uma relação entre um Elemento de Construção e qualquer Entidade, como um Frame, uma Construção ou um 
Elemento de Construção. Na próxima seção, serão demonstrados exemplos e aplicações das restrições bem como das relações de Herança e Evocação.

\section{Construções de Estrutura Argumental no PB}

As construções denominadas de estrutura argumental ganharam destaque principalmente nos trabalhos de Goldberg $(1995,2006)$. Segundo a autora, as construções de estrutura argumental são compostas por predicadores e seus respectivos argumentos. A proposta da GC nos permite associar uma estrutura sintática a um significado específico, uma vez que as construções de estrutura argumental representam ações humanas básicas e licenciam sentenças independentes de verbos particulares.

As construções analisadas nesse trabalho são de tipologia Sujeito - Verbo - Objeto (SVO) de período simples. Optamos por tratar dessas construções já que essas já foram descritas por diferentes linguistas em diferentes trabalhos, e por serem estruturas representativas de construções esquemáticas.

As análises que serão apresentadas nesta seção dizem respeito ao um conjunto de construções que tomam argumentos preposicionados em PB. Primeiramente, será apresentada a descrição de cada uma delas conforme as suas características sintáticas, semânticas e, juntamente, teremos a modelagem dessas construções no Constructicon da FN-Br. No total, serão apresentadas três construções - Transitiva Indireta, Transitiva Oblíqua e Bitransitiva.

\subsection{Construção Transitiva Indireta}

A partir das descrições realizadas por Castilho (2010), o qual apresenta estudos sobre a Construção Transitiva Indireta, propomos uma modelagem linguístico-computacional para essa construção. Castilho (2010) define que a construção Transitiva Indireta é composta por um argumento externo sujeito e um argumento interno objeto indireto, o qual seria proporcional a um pronome dativo, como lhe. As propriedades sintagmáticas e funcionais dessa construção também são exploradas pelo autor, assim, seria estruturada pela sequência [SN[SV[SP]] em que o sintagma nominal designa o sujeito e o sintagma preposicionado designa o objeto indireto ou beneficiário, conforme (1) e (2).

(1) O menino obedeceu à mãe.

(2) O prefeito respondeu ao jornalista.

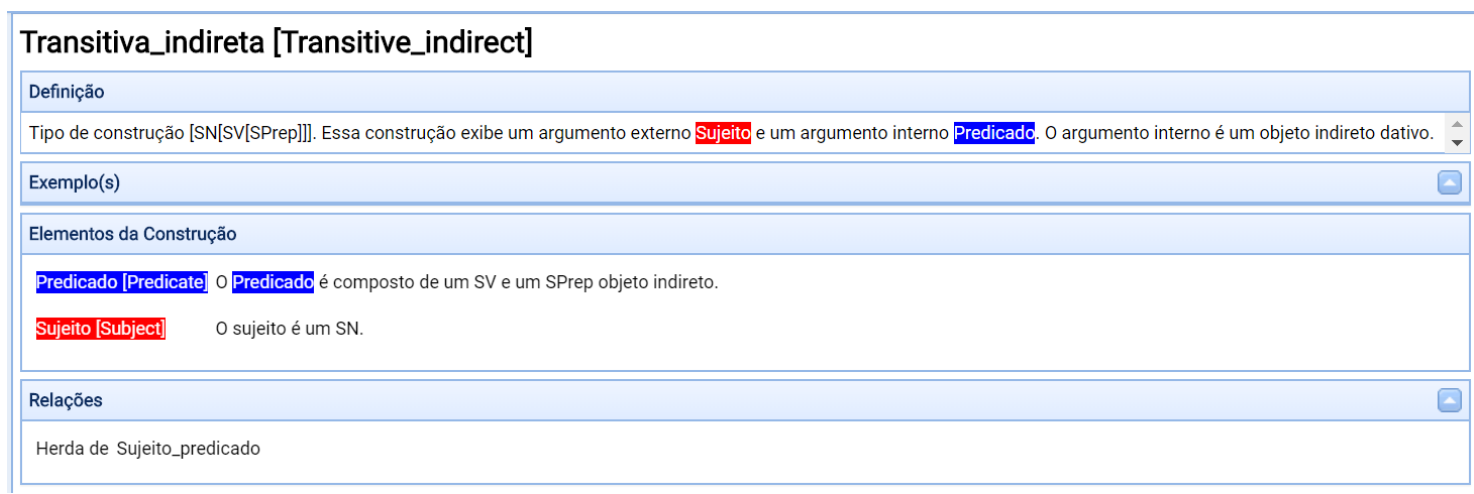

Figura 1. Construção Transitiva Indireta 
O processo de modelagem da Transitiva Indireta iniciou-se a partir da definição das suas propriedades sintáticas externas, o que demonstrou ser ela composta por dois Elementos de Construção (ECs), sendo um o Sujeito e o outro o Predicado, conforme Figura 1.

Outro aspecto relevante para o tratamento de construções diz respeito à modelagem de suas restrições de preenchimento. Assim, é possível estabelecer restrições de constituência para a construção a partir da definição dos ECs, uma vez que a constituência tipifica os signos filhos - os ECs - da construção em termos de outras construções. Dessa forma, enquanto os aspectos formais são considerados para a criação dos ECs, ou signos filhos, a informação semântica é atribuída através da unificação da construção com um frame. A aplicação das restrições à construção em questão é mostrada na Figura 2.

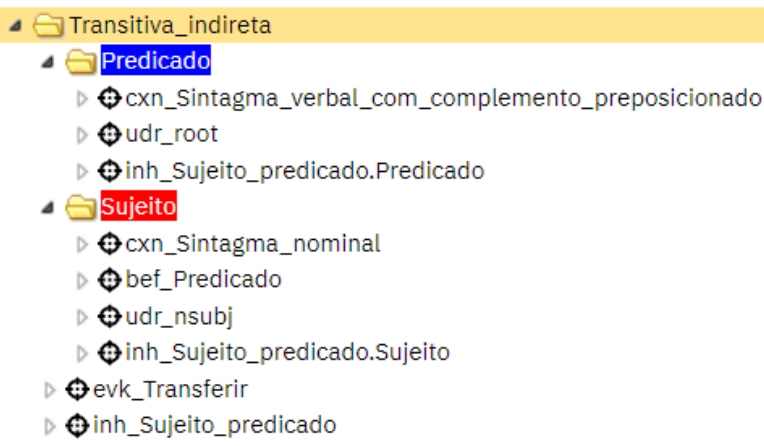

Figura 2. Restrições aplicadas aos CEs da construção Transitiva Indireta

Podemos observar na Figura 2 que o EC Predicado constitui uma construção de Sintagma verbal com complemento preposicionado, enquanto o EC Sujeito é constituído pela construção Sintagma nominal determinado.

Outras restrições que podem ser observadas na modelagem da Construção Transitiva Indireta derivam do comportamento dos ECs, que, na Figura 2 aparecem como CE. São elas: CE before, determinando que um dado EC deve vir antes de outro na sentença; $C E>$ Inheritance $>C E$ indica a relação de herança entre construções e a relação de herança entre ECs; $C E>$ UDRelation determina qual é a relação sintática do EC de acordo com as Universal Dependencies. No caso em tela, indicam que o Sujeito deve vir antes do Predicado; que o EC_Predicado é herdeiro do Predicado da Construção Sujeito_Predicado, o mesmo acontecendo analogamente com EC_Sujeito; e que o EC Predicado recebe a etiqueta root, por ser o núcleo dessa construção, enquanto o EC Sujeito recebe a etiqueta nsubj, indicando que ele é o sujeito dessa construção.

Além da constituência, uma operação denominada unificação, nos permite relacionar os ECs de uma construção ao frame por ela evocado, uma vez que os ECs da construção são relacionados aos EFs desse frame. Assim, o conjunto de propriedades de uma construção recebe o mesmo tratamento tanto sintático, como semântico. Conforme a modelagem realizada no Constructicon, a Construção Transitiva Indireta foi associada ao frame Transferir que consiste em um Doador realizando a transferência de um Tema para um Receptor.

\subsection{Construção Transitiva Oblíqua}

Há uma grande discussão na literatura gramatical a respeito da diferença entre o 
complemento oblíquo e o objeto indireto. A razão para essa discussão perpassa tanto questões morfossintáticas como questões semânticas. Nesse trabalho, optamos por seguir principalmente as considerações de Castilho (2010), assim como apresentamos a perspectiva diversa defendida por Rocha Lima (2007), que julga essa distinção principalmente pela natureza da preposição que encabeça o Sintagma Preposicionado. Segundo este último autor, o SP será um complemento dativo ou objeto indireto quando esse for por natureza [+humano ou +animado] introduzido pela preposição a com papel semântico de fonte ou alvo. Por outro lado, o sintagma preposicionado será um complemento oblíquo quando introduzido pelas preposições $a$, de, em, com e para com papéis semânticos de tempo, locativo e companhia.

Castilho (2010) mostra a Construção Transitiva Oblíqua como sendo composta por um argumento externo e um argumento oblíquo, que, segundo o autor, é comumente confundido pela Gramática Tradicional como o objeto indireto. A estrutura sintagmática e funcional dessa construção é [SN [SV [SP]]], em que o primeiro SN é o sujeito e o argumento oblíquo corresponde a um sintagma preposicional como em (3) e (4):

(3) Luís gosta de peras.

(4) Pedro precisa de notas.

Nos exemplos (3) e (4) temos os construtos licenciados pela Construção Transitiva Oblíqua. Em (3) o SN Luís corresponde ao sujeito, enquanto o SP de peras representa o argumento oblíquo, já em (4) o SN Pedro constitui o sujeito, enquanto o SN de notas constitui o argumento oblíquo.

Castilho (2010) chama a atenção para o fato de alguns pesquisadores classificarem o complemento oblíquo ora como adjunto adverbial ora como complemento terminativo. De acordo com Castilho (2010), tal argumento interno não pode ser considerado nem objeto direto nem objeto indireto, por não se possível comutá-lo com os pronomes "o" e "lhes", argumentando, diferentemente de Rocha Lima (2007), que apenas os sintagmas selecionados pelo verbo serão considerados argumentos. Sendo assim, o argumento oblíquo é uma exigência verbal e não uma atribuição preposicional.

A modelagem da Construção Transitiva Oblíqua no Constructicon mapeou que essa construção apresenta um Sujeito que corresponde a um Sintagma nominal e um Predicado que contém um verbo e um Sintagma preposicional. A modelagem mapeou também a relação de Herança com a construção Sujeito_Predicado e a relação Evocação com o frame Evento.

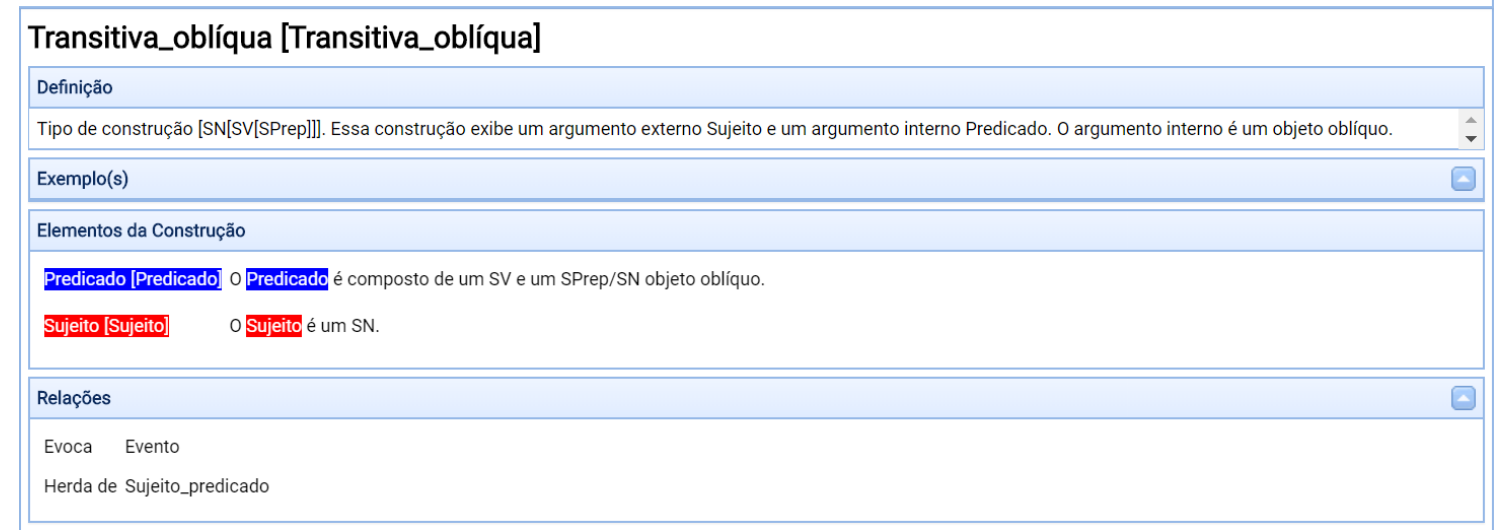

Figura 3. Construção Transitiva Oblíqua 
A Figura 3 mostra a Construção Transitiva Oblíqua com os ECs correspondentes e suas respectivas relações, e a Figura 4 mostra as restrições aplicadas aos ECs da construção que são similares as da Construção Transitiva Indireta, já que em relação à constituência ambas apresentam um Sintagma verbal com complemento preposicionado, mas conseguimos mapear a diferença em relação ao frame que cada construção evoca, uma vez que enquanto a Transitiva Indireta evoca o frame Transferir a Transitiva Oblíqua evoca oframe de Evento.

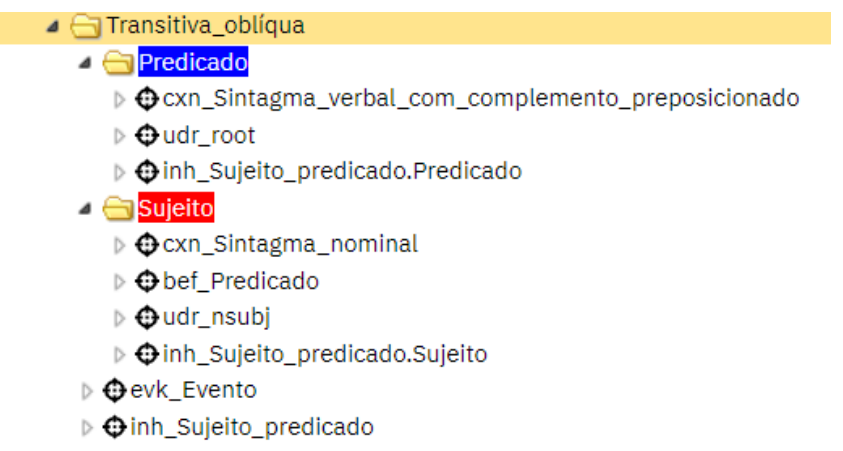

Figura 4. Restrições aplicadas aos CEs da Construção Transitiva Oblíqua

\subsection{Construção Bitransitiva}

A Construção Bitransitiva é também denominada triargumental. Diferente das construções biargumentais, essa construção, segundo Castilho (2010), é organizada de modo que temos um argumento externo e dois argumentos internos que podem ser representados pela estrutura sintática [SN [SV SN[SP]]]. Autores como Castilho (2010) e Perini (2010) afirmam a existência da construção em questão, uma vez que, na sua realização, temos a estrutura sintática composta por um Sujeito que corresponde a um Sintagma Nominal, outro Sintagma Nominal correspondente a um Objeto Direto e um Sintagma Preposicionado equivalente a um Objeto Indireto, como vemos em (7) e (8).

João deu um livro a Pedro.

O motorista colocou as malas no carro.

$\mathrm{Na}$ modelagem realizada no Constructicon, consideramos, portanto, as especificidades sintático-semânticas dessa construção. A composição sintática herdada da estrutura abstrata da construção Sujeito_Predicado é aquela em que o Sujeito é um SN agentivo e Predicado é um Sintagma verbal bitransitivo, composto por um SN e um SP, como podemos observar na Figura 5. Já a Figura 6 mostra a relação da Construção Bitransitiva ao frame por ela evocado e as restrições a ela aplicadas. Como o frame evocado pela Construção Bitransitiva é o frame Transferir que envolve um Doador transferindo um Tema para um determinado Alvo, a relação Evoca nos permite representar a contraparte semântica da construção em que o SN-Sujeito consiste no Doador e o Predicado, sendo um sintagma verbal bitransitivo composto pelas construções de Sintagma Nominal e Sintagma Preposicional, corresponde os EFs Tema e Receptor. Como vimos, a Construção Transitiva Indireta também evoca frame Transferir. Em relação ao frame, a diferença de uma construção para outra está no perfilhamento, apontado por Langacker (1991): enquanto na Transitiva Indireta o EF Tema é menos proeminente por se encontrar incorporado à raiz verbal, na Bitransitiva o Tema está 
configurado no SN e apresenta o mesmo grau de proeminência que o Doador e o Receptor, tendo a Construção Bitransitiva os três EFs do frame Transferir perfilados.

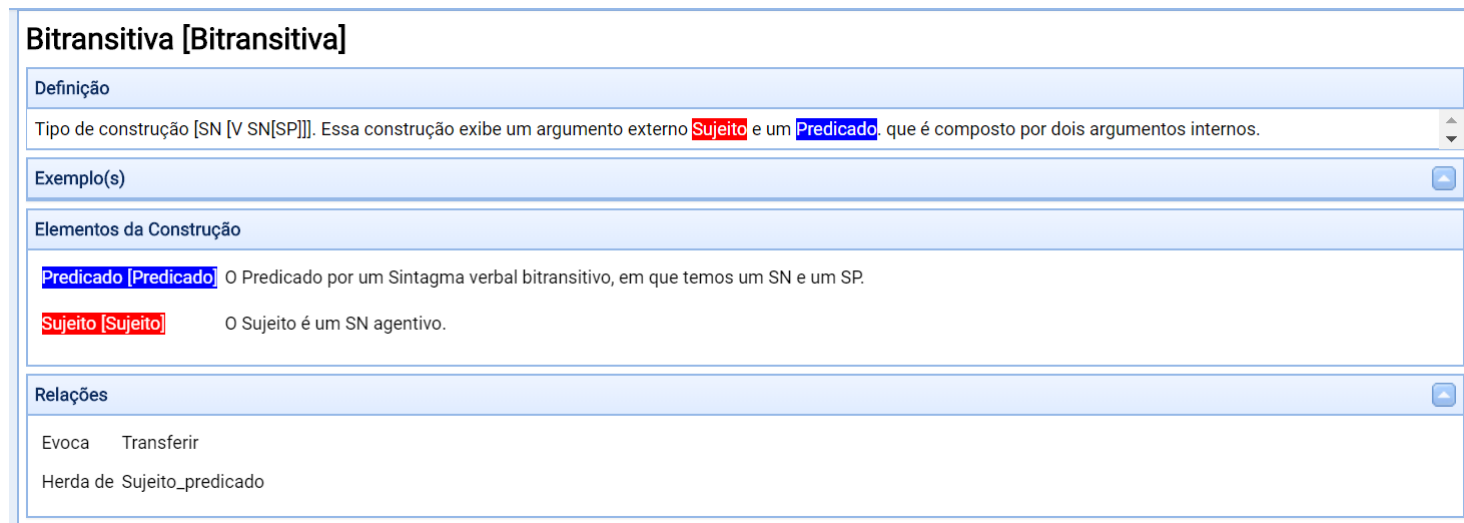

Figura 5. Construção Bitransitiva

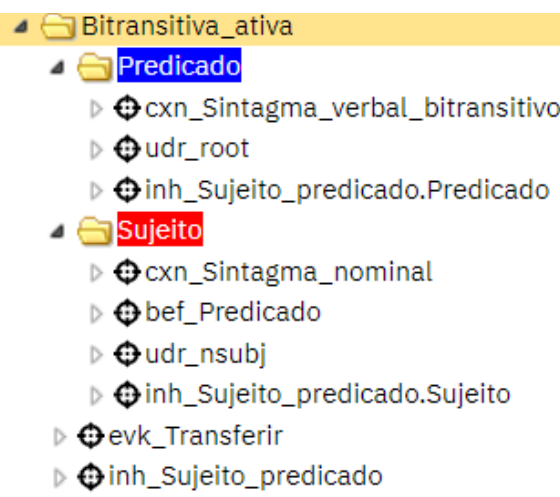

Figura 6. Restrições aplicadas aos CEs da Construção Bitransitiva

\section{Considerações Finais}

Neste trabalho apresentamos três construções, Transitiva Indireta, Transitiva Oblíqua. As construções que foram aqui modeladas explicitam a necessidade de considerar tanto aspectos semânticos como aspectos sintáticos para uma representação satisfatória do conhecimento linguístico. Para isso, de um lado, as restrições sintáticas foram tratadas em termos de sintagmas e categorias gramaticais como uma forma de mostrar as generalizações presentes em cada construção. Por outro lado, cada restrição foi unificada a um determinado componente semântico do frame evocado pela construção.

A proposta é abarcar no Constructicon diferentes construções de estrutura argumental com o intuito de constituir uma gramática do PB que inclua diferentes padrões construcionais, já que esses manifestam frames genéricos das ações humanas básicas, que já estão disponíveis na base da FrameNet Brasil.

O que propomos aqui ao aliar a teoria da Gramática de Construções com os recursos disponíveis da FrameNet Brasil é tentar modelar computacionalmente a cognição humana e os mecanismos que fundamentam o comportamento linguístico humano. Essa proposta tem no significado um papel crucial. Muitas vezes negligenciado em outros 
formalismos, o significado, aqui, deve ser incorporado às representações gramaticais com o fim de demonstrar como um modelo baseado em construções é cognitivamente plausível.

\section{Referências}

Almeida, V. G. (2016). "Identificação Automática de Construções de Estrutura Argumental: um experimento a partir da modelagem linguístico-computacional das construções Transitiva Direta Ativa, Ergativa e de Argumento Cindido”. Dissertação de Mestrado em Linguística. Universidade Federal de Juiz de Fora, Juiz de Fora.

Castilho, A. T. (2010). "Nova Gramática do Português Brasileiro". São Paulo: Editora Contexto.

Dias-da-silva, B. C. (2006) O estudo Linguístico-Computacional da Linguagem. In: "Letras de Hoje", v. 41, n. 2, p. 103-138.

Diniz da Costa et al. (2018) Representação computacional das construções de sujeitopredicado do português do Brasil. REVISTA LINGUÍSTICA, Rio de Janeiro, v. 14, p. 149-178.

Fillmore, C. J. (1982). Frame semantics. In: Linguistic Society of Korea (ed.), "Linguistics in the Morning Calm". Seoul: Hanshin, p.111-138.

Fillmore, C. J. (1985). Frames and the Semantics of Understanding. "Quaderni di semantica" 6 (2), p. 222- 254.

Fillmore, C. J (2008). Border conflicts: FrameNet meets construction grammar. In Bernal, E. \& DeCesaris, J. (eds.). "Proceedings of the XIII EURALEX International Congress". Barcelona: Universitat Pompeu Fabra, v. 4968, p. 49-68.

Fillmore, C. J. (2013). Berkeley Construction Grammar. In: Hoffmann, T. \& Trousdale, G. (eds.). "The Oxford Handbook of Construction Grammar". Oxford: Oxford University Press, p. 111-132.

Fillmore, C. J; Kay, P. \& O'Connor, M. (1988). "Regularity and idiomaticity in grammatical constructions: the case of let alone". Language, 64 (3), p. 501-538.

Goldberg, A. E. (1995). "Constructions: A Construction Grammar Approach to Argument Structure". Chicago: Chicago University Press.

Goldberg, A. E. (2006) "Constructions at Work: The nature of generalization in language”. Oxford: Oxford University Press.

Kay, Paul; Fillmore, Charles J. (1999). Grammatical constructions and linguistic generalizations: The 'What's X doing Y Construction? "Language", 75 (1), p.1-33.

Salomão, M. M. M. (2009). FrameNet Brasil: um trabalho em progresso. "Calidoscópio", 7(3), p. 171-182.

Silva, A. B. L. et al. (2017) In: “The AAAI 2017 Spring Symposium on Computational Construction Grammar and Natural Language Understanding Technical Report" SS17-02. Palo Alto, CA: AAAI Publications, v.17, p.193-196.

Torrent, T. T. \& Ellsworth, M. (2013). Behind the Labels: criteria for defining analytical categories in FrameNet Brasil. "Veredas", 17 (1), p. 44-65. 
ROCHA LIMA, (2007) “C. H. da. Gramática Normativa da Língua Portuguesa”. 46ª ed. Rio de Janeiro: José Olímpio Editora. 